\title{
Implementing Fully Privately Run Public Schools: Top View
}

\author{
Sheikh Muhamad Hizam Sheikh Khairuddin*, Kamaruzzaman Ismail**, and Zalina Zainudin* \\ University of Kuala Lumpur Business School, Malaysia* \\ Centre for Preparatory Studies (CPS), University of Kuala Lumpur (UniKL), Malaysia** \\ *Corresponding authorE-mail: sheikhmhizam@unikl.edu.my
}

\begin{abstract}
The aim of this paper is to identify the perceptions of teachers and regulators in implementing fully privately run public schools (FPRPS) in Malaysia. Under the Malaysian Educational Blueprint (MEB) 2013 - 2025, it is clearly stated that the programs and activities that would encourage and allow parents, the public and private sectors, NGOs, and society to forge a partnership with the school will benefit especially concerning values education. These school community partnerships can be related to the ninth shift in the Blueprint which is "partnering with parents, community and private sector at scale," although, the emphasis of this shift is more on students' academic progress. This study was conducted for three months' periods, involving 87 teachers and principals (in 13 schools) in the districts of Petaling Utama, Wilayah Bangsar-Pudu and Hulu Langat and 23 regulators in 10 Regulatory Bodies. The method used was in the form of focus group discussion (FGD). The data was processed by using Atlas ti. From the interviews conducted on FPRPS, all of the respondents (i.e. teachers, principals and regulators) indicated that they are ready and willing to accept the FPRPS implementation. This is because FPRS offers huge potential benefits to them. These include improvement in students' skill, teacher training, academic performance, employability, financial support, infrastructures, facilities, security, maintenance, workload, and school efficiency. The study contributes to the development of a new type of school in Malaysia.
\end{abstract}

Keywords: $M E B$, public-private partnership, feasibility study, teachers, regulators, fully privately run public schools, implementation, top view

\section{Introduction}

Public-private partnership (PPP) and privatization in education has been a global phenomenon recently ${ }^{1-2}$. Using student data, PPP schools in UK has been found to be significantly different in terms of quality of school management compared to government and private schools $\mathrm{s}^{3}$. The involvement of private companies in the education sector is particularly serious when the Malaysian government encourages partnerships especially in areas with high expertise. Smart partnership implementation can produce the following benefits:

- Saves the cost of system development

- Improve overall government agency performance

- Facilitate sharing of data and resources

- Improve skills, knowledge and expertise

- Reduce the gap between government agencies that are more capable with less-capable agencies in building IT applications

- Establish coordination between government agencies in IT development

- Assisting the overall economic development and recovery efforts of the country

Under the Ninth Malaysia plan, the government officially announced the implementation of public projects using the PPP or Private Finance Initiative (PFI) scheme ${ }^{4}$. The involvement of the private sector in delivering public facilities and services in education is not a new phenomenon in Malaysia ${ }^{5}$. Several form of PPP in education has been embraced in Malaysia including support services such as security, maintenance and canteen operation of school, trust school and adopted school.
What yet to be implemented in Malaysia is Fully Privately Run Public Schools (FPRPS) by private sectors or commonly known as full PPP. PPP in education is claimed to offer potential for overcoming some of the critical challenges and for developing the higher education subsector in developing countries ${ }^{6}$. Therefore, the objective of this study is to examine the perceptions and expectations as well as challenges and opportunities of stakeholders such as the teachers and regulators pertaining to the implementation of FPRPS in the country in the future.

\section{Literature Review}

An innovative idea to tap private resources, increase competition, and efficiency is through PPP7. School as a distinct social system has become an agent of change to the society. This is because the problem of society is a school problem too. In this case, inevitably communities need to cooperate with schools to achieve the ideals of schools and countries8. Smart or smart partnership is a strategic alliance that brings synergistic benefits to all parties involved. In the context of the public sectors, smart sharing takes place when agencies or companies share expertise, adopting experience or products in a field that has proven to be successful and appropriate. In 2012, the Ministry of Education (MoE) has launched the National Education Blueprint (2013-2025). The blueprint outlines 11 shifts required to transform the national education system to be on par with and comparable to that of developed nations, over the next 13 years. It was found that partners would like more active engagement and once created, need to be nurtured and extended so that there exists a strong as well as sustainable partnership system, which not only involves the active and participating of government (ministry of education) 
and Private sectors, but a very broad group of stakeholders. These stakeholders will need to provide "peripheral support in terms of policy enhancement, sustainable streams of funding, etc. and opportunities for continuous improvement". This active engagement necessitates also the need for a definition and restructure of the roles and responsibilities of partners9. Enabling equal power distribution between the partners is also essential and requires commitment to collaborative working at all levels. By establishing commitment to collaboration, school leaders (management) enable organizational networks to "mobilize support and overcome well-known barriers to sustaining collaboration"10, which is the aim of PPP initiative.

Senior managers involved in PPP implementation need to understand the strategic implications of current policy development and be appropriately equipped with "entrepreneurial, global management as well as change management skills" so that the boundaries of the system could be extended. It is important to have a "mutual respect for each other's areas of knowledge and expertise" "I1. If MOE wants their expectations met and their support appreciated, then they need to "listen to these professionals and recognize the value of the contribution they make"12, and the priorities they want to pursue ${ }^{13}$. All categories of staff should be involved in some capacity. The key question is not about how to convince the partner organization(s) of their capability, but rather, how the partner organizations together can improve their work ${ }^{14}$. This requires mutual commitment and responsibility ${ }^{15}$.

\section{Methodology}

Qualitative methods were used to collect data for this study. This involved focus groups discussions (FGD) and interviews between the teachers, principals and regulators. Teachers and principals' data were taken from 13 secondary schools from three districts namely, Bangsar-Pudu, Hulu Langat and Petaling Utama. Meanwhile, the regulators data came from 10 Federal and District Education Offices. A total of 87 teachers and principals (Table 1) and 23 Federal and District officers (Table 2) participated in the FGD and interviews conducted.

Thematic analysis was used to analyze the data from the interview and focus groups in order to identify the major issues that recur generated by the participants. Thematic analysis also allows the generation of the main themes that explain for the behaviors, actions and thoughts. Hence, the pattern and relationships discovered from the interpretation of the collected data was the basis of how the findings are structured. The stages in thematic analysis include Phase1: Familiarizing with the data; Phase 2: Generating initial codes; Phase 3: Searching for themes; Phase 4: Reviewing themes; Phase 5. Defining and naming themes and Phase 6: Producing the report. All interviews were audio recorded and were transcribed verbatim so as not to miss any important quotations or expressions. On average, the transcribing process lasted for four hours for each focus group. The researcher took two hours to translate relevant important quotations into English as most of the interviews were conducted in Malay. After the transcription process was completed, each transcript was saved in Microsoft Word file with a separate file name. The data was processed using Atlas ti - Windows 8 .

\section{Results and Discussion}

\section{Perception and Expectation of FPRPS Implementation}

To explore teachers and regulators perception and expectation towards FPRPS implementation, we asked them on the awareness first. The term 'aware' is used to describe the state where the observer (stakeholders) is conscious of events or thoughts without necessarily implying understanding. This dimension constitutes awareness in three situations. The data shows that generally participants were not aware of FPRPS. When they were interviewed by the researchers, the common respond was "I have never heard of it before, this is the first time", "I would say I never come across of this FPRPS". This indicates that participants were not having knowledge or conscious about the concept. Extending to this line of thought, when asked about their perception on the concept, there were participants who showed some level of knowledge. This second dimension recognizes awareness in the sense that they have heard about the concept but have no clue on the details. The following quote exemplifies the situation: "Someone talked about this before but it does not stick on my mind. I don't know how it works". The third dimension of awareness is when participants claimed that they have a basic understanding on the concept but not sure of the definite meaning. They perceived FPRPS as a concept familiar to them for instance model run at some trust school or vernacular school as quoted by participant "I have not heard of this fully run type of school but I have been to the trust school who are equipped with consultants like this one, from my understanding, this is like the SJKC model" (Participant SC4)

As a conclusion, based on the above findings, participants are generally have limited knowledge of FPRPS. Researches in many instances took the liberty to explain the concept of FPRPS in order to proceed with subsequent questions which would further scrutinize their perceptions and expectation towards FPRPS. The level of awareness is necessary because it helped the relevant participants to be more receptive to the concept. Hence the effort to create awareness among the stakeholders should be emphasized.

The second criterion investigated in this study is the readiness of respondents to the implementation of FPRPS. Below are some of their statements regarding readiness on FPRPS.

SC5: "We have no problem in adapting it"

SC3: "If it is me, I agree to it".

Most of the respondents interviewed stated that they are ready to accept the implementation of FPRPS.

Implementation area of concern was the next criterion discussed in the interview conducted. The respondents would like to have a pilot project conducted before the real implementation of the FPRPS:

SC11: "For sure, this involves a lot of costs. Maybe they can try one school and see how effective it is"

SC10: "For me, it is better to do a pilot first to avoid failure".

Some emphasized on the direction of the school.

$\mathrm{R} 1$ : "For me, what is the direction of the school. What do we want to become after this?"

Some regard the implementation as a good investment.

$\mathrm{R} 1$ : "This is an investment that is attractive to them".

The implementation area could also be based on corporate social responsibility.

R1: "That one I agree. For example, if you are a corporate body, the use of CSR system is good."

The teachers and principals are also concerned with workload and teacher training.

R1: "Managing in terms of workload should be emphasized more" R2: "For me, teachers should be given more training".

Some would like the changes be done gradually:

R3: "It should be done in stages..".

Others would see the implementation of this type of school would be based on profit and fees will be charged to the students:

R1: "I do not think the sponsor would want to sponsor if there is no profit. He will not waste his money"

R2: "Yes. More students are coming and certain fees will be charged. Because they have to make money from there" and "I think Al Amin charges RM 150 per month".

Some agree that only minimal fees will be charged to the students, as saying.

R3: "I agree to the minimally-charged fee..".

Some teachers and administrators commented:

R1: "The private sector will select their own staffs' son and daughters for the school" 
R2: "I do not like to choose student. So, the Ministry will decide which student is selected for the school"

R3: "It could be a high performance school whereby entrance to the school be based on UPSR results"

R4: "We could also have a placement test if a child wants to go into the school".

Some believe that the power will be given to the private sector to decide on that issue which will be reflected upon their performance and reward.

R1: "I think it will happen",

R2: "When it is privatized, the teacher will also be privatized, and we have to look at the benefits as well rather than hire and fire alone"

R3: "The implication for the teachers is that they will be given rewards but they have to look at their performance first".

There are also suggestions from the teachers and administrators to locate the school in the city, increase the capacity of the workforce in order to reduce the student-teacher ratio, and have a long-term plan.

R5: "If the school is in the urban area, it will have no problem"

R6: "Too many students in a class will make control more difficult"

R7: "It is better to have at least a 5 -year plan instead of 2 or 3 years plan first so that the students would not be a victim".

Some commented on the structure of FPRPS school:

R1: "If it is privately run, the structure might not follow the Ministry of Education's structure".

R2: "For example, the security guard once was under the government, now it will be under the private".

R3: "There could be two principals running the show:

one from the ministry while the other one from the corporate".

However, the curriculum might not be changed in contrast to school administration.

R4: "If it is private, the curriculum is still within our control. Only the scenario of management will shape the organization, but the content of the curriculum and teaching is still under control". There are suggestions that the FPRPS implementation should follow using several models such as the Kolej Vokasional (KV) Model and Sekolah Rendah Jenis Kebangsaan Cina (SRJK (C)) model. Below are their statements:

R1: "If it is my idea, we could follow the KV Model.

Then only you can see the difference for example, the salary paid is by the government. If you use this model, then it's ok.

The government gives per capita grant. Now, the grant is small. If it runs by the private company, the grant will be more. From that, the grant we pay to the teachers..".

$\mathrm{R} 2$ : "The truth is and based on my understanding, it looks like the SJKC Model"

R3: "One company for the school"

However, the source of fund can also come from the private sector.

R1: "If I am the principle, if it is going to be fully privately run, the private sector should give us the fund. Maybe, this fund is better than the government".

The school is still under the government.

R1: "But, we are still under the government, any actions are still subjected to the Acts".

There must be a clear direction from the government.

$\mathrm{SC} 1$ : "The government must set the direction they want to cover". In conclusion, most of the stakeholders are not aware of FPRPS or have minimal knowledge regarding it. In terms of readiness, they are willing to accept this new type of school since it offers positive benefits to them. This includes better facilities and infrastructure, better academic performance, etc. Regarding the implementation emphasis, the areas of concerned are pilot project, direction, expert from the industry, investment, corporate social responsibility, workload, teacher training, profit, fees, student selection, entry requirement, performance, reward, location, workforce capacity, teacher-student ratio, long-term plan, structure, model, source of fund, act, and clear direction.
Challenges and Opportunities in Managing FPRPS

Teachers and principals have identified a number of potential challenges in managing FPRPS if were given a chance. Fees are some of the concern of the respondents.

SC2: "When we talk about private, it means increase in cost. If you look at the environment here, in terms of economic areas, we will have problems. Parents income here are well below RM3,000 per month."

Other respondents addressed the issue of moral.

$\mathrm{SC} 1$ : "When the objective is to make a profit, other areas such as moral is being neglected."

Work-life balance is also being discussed during the interview.

SC4: "We also have to work on Saturdays probably. We chose to work under the government because we want to spend more time with our family. However, if we are privatized, the time with our family will be limited."

The respondents are also worried about their pension plan.

SC11: "I have an anxiety about my pension plan once the school is taken over by the private sector. "

Teacher stress is also being highlighted in the discussion.

SC5: "When outsiders came in, there will be restructuring. This will be stressful for the teachers. Lesson plan will be longer. Therefore, the teaches will be exhausted..".

There is also a weakness in this type of school if they impose a higher fee to the students' particular for those who are in the urban poor category.

SC1: "Although our school is located in the urban area, however the population is mostly poor."

Another concern is that this type of school is that it still under the jurisdiction of the government. Therefore, any actions are subjected to the laws.

SC11: "Since we are still under the government, any actions are subject to the education acts and laws. "

For the regulators, their concerns are as such:

R1: "There will be constraints in terms of regulation when the FPRPS is implemented."

There are also issues of managing people:

R2: "When the private comes in, there will be a conflict in terms authority and hierarchy."

Therefore, a clear structure has to be established:

R3: "Structure regarding hire and fire, curriculum, and fees should be established."

Infrastructure and fess are also highlighted:

R1: "The infrastructure and facilities like auditorium, etc. should be upgraded like the private school."

There are some threats to this type of school such as sustainability. $\mathrm{SC} 2$ : "We have to consider a lot of things, especially the number of students and money from the government."

There are also teachers and principals' resistance to this change.

SC2: "This is my personal opinion. I do not agree my school to be transformed to FPRPS. As an educator, I feel that the teachers must set the direction."

SC3: "We have to follow new orders from outsiders"

SC5: "I am already old. At the age of 50, I believe my faith is with the government. The young ones will also feel the pain economically for example, transfer, new homes, and so on. The private sector will only look for the best"

SC7: "For me, I do not think about the incentives, but the strength in getting the things done"

SC8: "Where do we put our current administrators if an outsider comes in?"

Several opportunities can be derived from the interviews conducted earlier such as improved their skills, teacher training, academic performance, and employability more funds and better infrastructure, workload, security and maintenance, school efficiency, productivity, and teacher's skills, profit, and salary.

This type of school can focus on the skill of the students:

SC2: "There are some students who excel in academic and there are some who are very skillful" 
SC5: "We can divide the time to cater for both skills and academic classes. As you know, right now Malaysia is facing a shortage of skill workers"

SC7: "They must also be given a certificate for them to work"

This is also an opportunity for the school to improve their teacher training, academic performance, and employability

$\mathrm{SC} 1$ : "The teachers were given very well training and the examinations set were set by the company and the students' attendance is 95 per cent above and their result is good so they will take them to work in their company. So, there's a promise for the future."

There is also opportunity for government school to receive more financial support due to the fact that government is not pumping sufficient funds to the school anymore:

SC3: "Right now, this school is a government school but we also depend on the community to help us particularly from the NGO. If not, we won't have enough money to sustain and maintain the school because the government is not pumping in that much."

Most of the respondents agree that FPRPS will provide more funds that will provide better infrastructure and facilities.

R1: "More funds will be provided by having a private company runs it to cater for school activities for example", "In terms of the facilities, the private sector can improve on that", "In terms of infrastructure", "..such as computer lab and LCD...", "..van and busses..", "books", "modern science lab and equipment", and "aircondition".

Hence, this will help in implementing the 21st century of teaching and learning concept, as quoted: "..chairs can be formed in a circle and tables are different than ours".

The teachers and principals also have views that their work load will be reduced with additional support staff provided by the private sector:

SC1: "Let say the private runs the school, the warden no longer is a teacher but a specialized warden will be there."

This will also make the academic more focused on teaching rather than doing administrative duties.

SC4: "We can focus on teaching without thinking other stuff.

Others also think that security and maintenance will also be improved with a private company running it."

SC6: "We do not need to be worried of security and maintenance such as fighting, playing truants, cleaning, and gardening because the private sector will manage it well."

The strength of FPRPS can be said to be in-line with the Malaysian Education Blueprint for 2013-2025.

R1: "It is parallel with the second wave of shift involving the private sector"

The inclusion of the private sector can help improved school efficiency, productivity, and teacher's skill.

$\mathrm{R} 1$ : "Maybe when it is privatized, the work culture changes, such as work must be done quickly."

R2: "I agree with the concept of productivity by the private sector. We pay for hire and we fire. It looks cruel but this method is used extensively in the education sector in the developed country. We hire you because you are good"

However, teachers and principals might have to work late pertaining to the new KPI derived from the private sector: The strength of this type of school could be based on profit. SC2: "Nobody likes to take or to repair, unless he wants to make a profit like the private sector"

Other teachers and administrators view FPRPS as strength in terms of providing a new or better choice for the parents to send their kids there.

R1: "Parents want more choices for their kids' education"

The salary will increase in FPRPS.

R1: "If they increase the salary, it is ok by me. It is good to have an incentive like that because our basic is only RM2500."

In conclusion, the challenges of the teachers are as follow: fees, moral, work-life balance, pension plan, stress, urban poor, and act. Meanwhile, for the private sectors, the challenges that they might face if they take this project are profit, policy, charges, and autonomy. Finally, are the challenges as highlighted by the regulators. They are: operation and legal conflict, management, clear structure, and

infrastructure and funds. In terms of opportunities, these includes improvement in students' skill, teacher training, academic performance, employability, financial support, infrastructures, facilities, security, maintenance, workload, school efficiency, productivity, teachers' skill, profit, and salary.

\section{Conclusion}

There are several conclusions can be drawn from this study. In the findings from the interviews conducted, all of the respondents i.e. teachers, principals, and regulators expressed their readiness and willingness in accepting the FPRPS implementation. The regulators are the most favorable group in accepting FPRPS. These positive results are due to the fact that there are huge potential benefits in FPRPS implementation. These includes improvement in students' skill, teacher training, academic performance, employability, financial support, infrastructures, facilities, security, maintenance, workload, school efficiency, productivity, teachers' skill, profit, and salary.

Teachers and principals also are ready and willing to accept FPRPS. However, they have certain ambiguity. With the inclusion of the private sector in their school, they fear that their salary, benefits, workload, and career path could be in jeopardy. For future research direction, we would like suggest that a nationwide survey being conducted in order to strengthen these findings.

\section{Acknowledgments:}

This research project is financially supported by Performance and Delivery Unit (PADU), Ministry of Education (MOE), Malaysia.

\section{References}

[1] M. Afridi. PPPs in global education policy: Looking at the case of the Egyptian Education Initiative. Advances in Education in Diverse Communities: Research, Policy and Praxis, 12, (2017).

[2] Verger, C. Fontdevila, and A. Zancajo. Multiple paths towards education privatization in a globalizing world: a cultural political economy. Journal of Education Policy, 32, 6, (2017).

[3] L. Crawfurd. School management and public-private partnerships in Uganda. Journal of African Economies, 26, 5, (2017).

[4] Ninth Malaysia Plan. http://www.epu.gov.my/en/rmk/ninthmalaysia-plan-2006-2010 (2006)

[5] A. Hamilton. The Malaysian Trust School Model: It's good but is it sustainable? Policy Ideas No 11, February (2014).

[6] Asian Development Bank. Bangladesh: Public-Private Partnership in Higher Education Technical Assistance Consultantes Report, ADB.(2014).

[7] J. Kumari. Public-private partnerships in education: An analysis with special reference to Indian school education system. International Journal of Educational Development, 47, (2016).

[8] Mamat. Pengetua sekolah: Menangani isu dan cabaran kepimpinan. Kumpulan Budiman Sdn. Bhd. Kuala Lumpur (2001).

[9] S. McCray, Y. N. Zhang, and J. Q. Chen. Preventing the achievement gap: Professional development in foundational mathematics. Paper presented at the annual meeting of the National Council of Teachers of Mathematics, Indianapolis, IN. (2011).

[10] M. Harris. Interdisciplinary strategy and collaboration: a case study of American research universities, Journal of Research Administration. XLI, 1, (2010).

[11] R. Briggs., I. Hall, D. Mercer, F. Smith, T. Swannm, and C. Falzon, C. Leading partnerships for 14-19 Education provision, Research Report, Centre for Excellence in Leadership (2007).

[12] R. Benefer, D. Jenkins, and K. McFarlane. The HE in FE experience and culture for staff, Higher Education Learning Partnership [HELP] and Centre for Excellence in Teaching and Learning [CELT] Conference Proceedings (2009). 
[13] Bosma, R. Sieving, A. Ericson, P. Russ, L. Cavender, and M. Bonine. Elements for successful collaboration between K-8 school, community agency, and university partners: The lead peace partnership, Journal of School Health, 80, 10, (2010).

[14] P. Rogers, A. Whitney, A. Bright, R. Cabe, T. Dewar, and S. Null. Rejoining the learning circle: when in-service providers conduct research, English Education, 43, 2, (2011).

[15] Sigurdardottir. School-university partnership in teacher education for inclusive education, Journal of Research in Special Educational Needs, 10, 1, (2010).

Table 1: Distribution of Teachers and Principles

\begin{tabular}{|l|c|c|}
\hline School & Coding & $\begin{array}{c}\text { No. of } \\
\text { Teachers and } \\
\text { Principals }\end{array}$ \\
\hline SMK Bandar Baru Ampang & SC1 & 6 \\
\hline SMK Bandar Tun Razak & SC2 & 7 \\
\hline SM Teknik KL & SC3 & 8 \\
\hline SMK Sri Aman & SC4 & 6 \\
\hline SMK Seri Hartamas & SC5 & 6 \\
\hline SMK Tinggi Kajang & SC6 & 8 \\
\hline SMK Aminuddin Baki & SC7 & 6 \\
\hline SMK Tropicana & SC8 & 6 \\
\hline SMK Seri Bintang Utara & SC9 & 7 \\
\hline SMJK Yu Hua & SC10 & 7 \\
\hline SMK Bdr Baru Bangi & SC11 & 9 \\
\hline SMK Jln 4 & SC12 & 6 \\
\hline $\begin{array}{l}\text { SMK International Islamic Holistic } \\
\text { Schools }\end{array}$ & SC13 & 5 \\
\hline Total & & $\mathbf{8 7}$ \\
\hline
\end{tabular}

Table 2: Distribution of Regulators

\begin{tabular}{|l|c|c|}
\hline Regulators & Coding & $\begin{array}{c}\text { No. of } \\
\text { Participants }\end{array}$ \\
\hline Selangor's Department of Education & R1 & 3 \\
\hline Wilayah's Department of Education & R2 & 3 \\
\hline $\begin{array}{l}\text { Petaling Utama's Education District } \\
\text { Office }\end{array}$ & R3 & 3 \\
\hline Hulu Langat's Education District Office & R4 & 2 \\
\hline Bangsar/Pudu's Education District Office & R5 & 4 \\
\hline $\begin{array}{l}\text { Malaysia's Education Ministry } \\
\text { Education Policy Research and } \\
\text { Assessment Sector }\end{array}$ & R6 & 3 \\
\hline $\begin{array}{l}\text { Malaysia's Education Ministry } \\
\text { Daily School Management Division }\end{array}$ & R7 & 1 \\
\hline $\begin{array}{l}\text { Malaysia's Education Ministry } \\
\text { Drafting of Law and Education Policy } \\
\text { Sector }\end{array}$ & R8 & 2 \\
\hline $\begin{array}{l}\text { Malaysia's Education Ministry } \\
\text { Technical and Vocational Education } \\
\text { Division }\end{array}$ & R9 & 1 \\
\hline $\begin{array}{l}\text { Malaysia's Education Ministry } \\
\text { Islamic Education Division }\end{array}$ & & $\mathbf{2 3}$ \\
\hline Total & R10 & 1 \\
\hline
\end{tabular}

